\title{
Pollen Sensitization Among Egyptian Patients With Respiratory Allergic Diseases
}

\section{Manar Farouk Mohamed ( $\nabla$ drmanarfarouk86@yahoo.com )}

Ain Shams University Faculty of Medicine https://orcid.org/0000-0002-6998-6889

Maged Mohamed Refaat

Ain Shams University Faculty of Medicine

Nermine Abd El-Nour Melek

Ain Shams University Faculty of Medicine

Eman Al-Sayed Ahmed

Ain Shams University Faculty of Medicine

Nada Mohamed Noor Al-Din

Ain Shams University Faculty of Medicine

Osama Mohamed Abdel Latif

Ain Shams University Faculty of Medicine

\section{Research}

Keywords: allergic rhinitis, bronchial asthma, grass pollen, pollinosis

Posted Date: February 9th, 2022

DOI: https://doi.org/10.21203/rs.3.rs-1284612/v1

License: (c) (i) This work is licensed under a Creative Commons Attribution 4.0 International License.

Read Full License 


\section{Abstract}

Introduction: Pollen is responsible for seasonal allergies, such as allergic rhinoconjunctivitis (AR), and has become a growing public health concern. Climate change affects the range of allergenic species as well as the timing and length of the pollen season. In Egypt, data on pollinosis are scarce.

Objectives: To detect the most prevalent pollen causing allergies among Egyptian patients with respiratory allergies.

Methods: A total of 200 adult patients with respiratory allergic diseases (AR) and/or bronchial asthma (BA) were included. Medical history taking and physical examinations were conducted on each patient, and complete blood count (CBC) and total immunoglobulin E (IgE) determination, spirometry, specific $\lg E$, and skin prick tests (SPTs) and for common aeroallergens and food were performed.

Results: Of the 200 patients, 106 were females; the mean \pm standard deviation was $34.42 \pm 13.0$ (range, 16 to 66 ), and $65 \%$ were living in urban areas. Grass pollen, mainly from Timothy grass and maize, were the most prevalent (28.5\%). Timothy grass was the most common type of pollen in patients with AR (28.3 $\%)$. Elder pollen showed significance among asthmatic patients $(P=0.004)$. Bermuda grass was statistically more prevalent in rural than in urban areas $(P$ value $=0.008)$. Maize was linked to uncontrolled BA, whereas Timothy grass was the most prevalent among patients with moderate/severe AR. Forty-three patients had oral allergy syndrome; oranges and tomatoes were the most cross-reactive food ( $12 \%$ and $11.5 \%$, respectively). Exacerbation of allergic symptoms was noted during January, December, March, and June.

Conclusion: Pollen plays a substantial role in affecting patients with respiratory allergies in Egypt. Grass pollen is the most prevalent type of pollen, especially in urban areas.

\section{Introduction}

Allergic airway diseases, such as bronchial asthma (BA) and allergic rhinoconjunctivitis (AR), are major health and economic burdens because of their impact on quality of life, including social life, school attendance, and work performance [1]. Both genetic and environmental factors contribute to the development of allergic airway diseases, and one of the major environmental determinants causing respiratory allergy is pollen [2]. Pollinosis is characterized by a periodic repetition of symptoms during a specific pollen season that varies between countries. Patients sensitized to both seasonal (e.g., pollen) and perennial allergens (such as house dust mites (HDM), cockroaches, and molds) have year-round symptoms of respiratory allergy and experience exacerbation during the pollen season [3]. Although the pollen season is related to the flowering season, air pollution and climate change are the main influencers of pollen allergenicity. Pollution, mainly in urban areas, leads to an increase in the pollen allergenic protein concentrations, with modifications of unexpressed proteins into more allergenic components that induce allergies in sensitized individuals [4]. On the other hand, climate change affects the timing and length of the pollen season [5] as well as their geographical extent and distribution [6]. 
Grasses, weeds, and trees are the main sources of pollen allergens. Grass pollen, with its abundant production and wide distribution, is responsible for $40 \%$ of pollen sensitization [7]. Many studies in the United States showed that tree pollen was responsible for 25,000-50,000 hospital visits due to asthma during spring, whereas grass pollen was responsible mainly for summer visits [8]. On the other hand, weeds are more prevalent during fall [9]. Parietaria, ragweed, mugwort, sunflower, and Russian thistle are the main sources of weed pollen worldwide [10]. Cross-reactions between plant-derived allergens and aeroallergens in previously sensitized patients lead to oral allergy syndrome (OAS). OAS is an immediate hypersensitivity reaction that occurs when raw fruits or vegetables come into contact with the oral mucosa, resulting in itching of the lips, tongue, and throat [11]. OAS may be associated with more severe symptoms, such as angioedema or anaphylaxis, in $2-10 \%$ of cases. The main allergenic components involved in OAS are profilins, pathogenesis-related protein 10, and lipid transfer proteins [12]. As only few studies have reported the prevalence of pollen allergy in Egypt, our study aimed to determine the most prevalent types of allergenic pollen among Egyptian patients with respiratory allergies.

\section{Patients And Methods}

\subsubsection{Patient selection criteria}

This cross-sectional study involved 200 adult patients ( $\geq 16$ years old) who were newly diagnosed with respiratory allergic diseases, such as BA and/or AR, according to the GINA [13] and ARIA guidelines [14], respectively, and were recruited from the allergy clinic at Ain Shams University Hospitals from November 2017 to November 2019.

\subsubsection{Exclusion criteria}

Patients who were receiving allergen-specific immunotherapy or those who recently received antihistamines or any drug that might interfere with the skin prick test (SPT) results were excluded from the study. Patients with dermographism and pregnant females were also excluded.

\subsection{Methods}

All patients were subjected to detailed medical history taking, including the frequency and timing of symptoms, history of pollen exposure, associated allergic conjunctivitis or OAS, assessments of asthma symptom control and AR severity using the GINA and ARIA guidelines, respectively, and spirometry for assessments of lung function and asthma control. From the peripheral blood samples, the CBC was obtained to determine the absolute eosinophilic count as well as the total IgE. SPTs and specific IgE for common environmental aeroallergens and food allergens were also performed.

\subsubsection{SPT}

Briefly, drops of standard allergen extract provided by Bencard (Allergy Therapeutic Ltd., England) were introduced on the volar aspect of the patient's forearms while carefully pricking the skin using a blood lancet, and the results were interpreted after 20 minutes. Wheals $\geq 3 \mathrm{~mm}$ were considered positive [15]. 
Allergen extracts used in the SPT included different allergenic pollen (Bermuda grass, maize pollen, rye (cultivated), Timothy grass, wheat (cultivated), mugwort, ragweed, Russian thistle, alder, birch (silver), elder, olive), and other common allergens such as Alternaria alternata, Aspergillus fumigatus, cat fur, HDM (Dermatophagoides farinae and Dermatophagoides pteronyssinus), common food allergens (mixed nuts: almond, Brazil, chestnut, hazelnut, walnut), orange, tomato, soya flour, wheat grain, whole egg, and cow's milk.

\subsubsection{Serum total $\lg E$}

An enzyme-linked immunosorbent assay was used for the quantitative determination of the total IgE level in human serum.

\subsubsection{Specific IgE}

Is an enzyme immunoassay For quantitative values of specific $\lg E$. The involved allergen specific $\lg E$ were [Bermuda grass, maize pollen, rye, Timothy grass, wheat, mugwort, ragweed, Russian thistle, alder, birch, elder, olive, Alternaria alternata, Aspergillus fumigatus, cat fur, Dermatophagoides farinae and Dermatophagoides pteronyssinus ], specific $\lg E$ is consided positive if $\geq 0.35 \mathrm{IU} / \mathrm{mL}$ [16 ].

\subsubsection{Spirometry}

After the determination of patients' sex, age, height, and weight, patients were asked to fully inhale before beginning forced exhalation [17]. The flow-volume curves and the volume-time curves were then displayed [18]. Numerical values were given only for the forced expiratory volume in 1 second (FEV1), forced vital capacity (FVC), and FEV1/FVC ratio. Grades of severity of obstructive airway diseases were interpreted according to the American Thoracic Society guidelines [19].

\subsection{Statistical analyses}

The data collected were revised, coded, tabulated, and introduced to a PC using the Statistical Package for Social Sciences (SPSS v20). Data were presented and analyzed according to the type of data obtained for each parameter. Parametric numerical data are presented as the mean \pm standard deviation and range, whereas nonparametric numerical data are presented as the median and interquartile range (IQR). The chi-squared test was used to examine the relationship between two qualitative variables. $\mathrm{P} \leq$ 0.05 was considered statistically significant.

\section{Results}

A cross-sectional study was conducted on 200 adult patients ( $\geq 16$ years old) with newly diagnosed AR and/or BA who were randomly selected from an allergy and immunology clinic at Ain Shams University Hospital. All patients underwent detailed medical history taking and physical examinations; spirometry, $\mathrm{CBC}$, and total IgE levels were obtained; and SPTs for common aeroallergens and food were performed. 
The demographic data show that 106 (53\%) were females. The mean age of the patients was $34.42 \pm$ 13.0 years (range, $16-66$ years). The majority of patients were living in urban areas (65\%), and $60.5 \%$ had positive family history of atopy. AR was the most frequent respiratory allergy (117 patients), whereas 56 patients had both AR and BA.

Regarding the severity of AR, $51.4 \%$ patients had moderate to severe intermittent AR, $41 \%$ had moderate to severe persistent AR, $5.2 \%$ had mild intermittent AR, and $2.3 \%$ had mild persistent AR. Regarding BA control symptoms, $72.3 \%$ of patients had partially controlled asthma, $18.1 \%$ had controlled asthma, and $9.6 \%$ had uncontrolled asthma. In our study, 43 patients $(21.5 \%)$ had OAS. The median absolute eosinophil count was 130 (IQR, 75-280) cells $/ \mathrm{mm}^{3}$, whereas the median total IgE level was 90 (IQR, 35225) $\mathrm{IU} / \mathrm{mL}$.

The results showed that $93 \%$ of the study population had a positive SPT, and 171 (85.5\%) patients were sensitized to pollen. Dermatophagoides pteronyssinus was the most prevalent allergen (32\%) causing atopy, followed by Timothy grass (28.5\%), maize pollen (28.5\%) and D. farinae (28\%) (Table 1 ).

The majority of patients were sensitized to grass pollen, which included Timothy grass, maize, and Russian thistle, whereas tree pollen caused the least sensitization among the pollen (Figure 1).

In this study, the months when patients reported the peak of their symptoms were January (26.5\%), December (21.5\%), March (18\%), and June (16\%) (Figure 2).

The most prevalent pollen causing respiratory allergy in rural and urban areas was Timothy grass (34.3\%) and maize pollen (29.2\%), respectively. Regarding Bermuda grass, its prevalence in rural areas was significantly different from that in urban areas $(P<0.008)$ (Table 2$)$.

It was found that $145(66.8 \%)$ patients with AR had pollen allergy, whereas $72(33.2 \%)$ patients with BA were sensitized for pollen allergens. Elder pollens were the most statistically significant pollen among asthmatics $(P<0.004)$, whereas Timothy grass was the most prevalent pollen among patients with AR (28.3\%). Patients who had mild intermittent AR (9) showed the greatest number of positive results to alder and maize (33.3\%), whereas patients with mild persistent AR (4) showed the greatest number of positive results to Bermuda grass, Russian thistle, cultivated rye, and wheat pollen. In addition, patients with moderate/severe intermittent AR (89) showed the greatest number of positive SPT results to maize pollen (29.2\%). Moreover, patients who had moderate/severe persistent AR (71) showed the greatest number of positive SPT results to Timothy grass pollen (32.4\%) (Table 3).

Patients with controlled asthma (15) showed the greatest number of positive results to alder pollen (26.7\%). Patients with partially controlled asthma (60) showed the greatest number of positive results to maize pollen (30\%). Patients with uncontrolled asthma (8) showed the greatest number of positive results to maize pollen (37.5\%) (Table 4).

Moreover, the most prevalent cross-reactive food allergens in this study were oranges (12\%), tomatoes (11.5\%), and soya (11\%). Tomatoes were highly cross-reactive with Timothy grass (43.5\%) and maize 
pollen (39.1\%). Oranges were highly cross-reactive with cultivated rye and Russian thistle (33.3\%). Soya was highly cross-reactive with cultivated rye (36.4\%), Timothy grass (27.3\%), and Russian thistle (27.3\%) (Table 5).

\section{Discussion}

Pollen is divided into three main groups: grasses, weeds, and trees. Our study aimed to determine the most prevalent allergenic pollen among Egyptian patients with respiratory allergies (AR and/or BA). The study was conducted on 200 adult patients with newly diagnosed respiratory allergies.

Most of our patients with respiratory allergies were living in urban areas (65\%), which agreed with a previous study that demonstrated that patients living in urban areas had a higher prevalence of polleninduced AR than patients living in rural areas $(23.1 \%$ versus $14.0 \%, P<0.001)$ [20].

This observation was previously explained by David Strachan, who noticed a reduced prevalence of asthma among children living on farms as increased exposure to pathogens during childhood resulted in tolerance to different allergens. He concluded that living in urbanized areas leads to reduced pathogen exposure, with a subsequent high risk of allergy [21].

In a study on 25,393 women, residents of rural areas had a lower odds ratio of developing allergies than residents of urban areas, relying on the fact that the former lived in areas with low levels of pollution, thus avoiding traffic-related air pollution, which is the main environmental cause of the high prevalence of allergies in urban areas [22]. Another fact supporting our results was that carbon dioxide (released in urban areas) acts as an important nutrient to plants, which allows the growth of a greater number of plants producing different allergenic pollen in urban areas, resulting in an increased allergy prevalence [23].

$21.5 \%$ of our patients complained of OAS symptoms. Two large Korean studies conducted on patients with respiratory allergy had results similar to ours, with the prevalence of OAS ranging from $20.0-41.7 \%$ $[11,24]$.

Regarding the SPT results, 186 patients had positive SPTs for different allergens. We detected a higher prevalence of people allergenic to HDM (D. pteronyssinus, 32\%), followed by Timothy grass $(28.5 \%)$, maize grass pollen $(28.5 \%)$ and $D$. farinae $(28 \%)$.

Previous studies reported that $45-85 \%$ of patients with respiratory allergies were SPT-positive to HDM [25]. Frankland and El-Hefny were the first to point out the high prevalence of people allergenic to HDM in Egypt, especially $D$. farinae, attributing Egypt's dry climate as a major reason behind the high prevalence. Since then, many studies have confirmed the widespread presence of HDM and other mites in domestic settings across Egypt and in the Middle East [26].

The prevalence of pollen allergy differs globally by region, depending on the climatic conditions. For example, Middle Eastern countries are known to have a dry, desert-like climate. Moreover, countries such 
as Egypt also have coastal regions with a Mediterranean climate [27]. Besides the effects of climate on the high diversity of pollen worldwide, introducing invasive allergenic pollen increases pollen prevalence, with new pollen sensitization [28].

In this study, grass pollen was the most frequent pollen allergen that patients were sensitized to, with $28.5 \%$ of patients reacting to Timothy grass and maize grass pollen. This was followed by Russian thistle $(24 \%)$ and cultivated rye $(23 \%)$, which are in contrast to tree pollen that has less frequent sensitization (elder, $7 \%$; birch, $6 \%$ ). Our results agree with the fact that grass pollen is one of the most frequent reasons for plant-related allergenic reactions worldwide. It is thought that at least $40 \%$ of patients with respiratory allergies worldwide are sensitized to grass pollen allergens [29], which comprise 9,000 different grass species (Poaceae) [30]. Timo et al. demonstrated that grass was the most frequent cause of pollen allergy in Europe and the USA. This is because grasses grow on every continent and in almost all types of environments. Grasslands were estimated to constitute $20-30 \%$ of the vegetation covering Earth, which explains the large percentage of grass pollen allergy globally [31]. Comparative studies from Middle Eastern countries, which include Egypt, Jordan, Kuwait, and the Kingdom of Saudi Arabia (KSA), showed that grass pollen was the most frequent allergen responsible for respiratory allergies among patients, with Bermuda grass being the most frequent in Kuwait and KSA [32-35].

On the other hand, a Chinese study that included 6,043 patients with AR revealed that most of these patients were sensitized to weed pollen [20]. Another study by Sung et al. in Korea found that the sensitization rate to trees (25.2\%) was the highest among pollen types, with birch pollen being the highest among tree pollen (10.3\%), followed by weeds (19.9\%) (mugwort and ragweed) [36].

We found that $66.8 \%$ of patients with AR had pollen allergy, whereas $33.2 \%$ of patients with BA were positive to pollen allergens. The most prevalent pollen in patients with BA was maize pollen (26.5\%), whereas Timothy grass pollen was the most frequent (28.3\%) in patients with AR. In our study, tree pollen (elder) was significantly more prevalent in patients with asthma than in patients with AR. This could be explained by the fact that grass pollen, because of its large size, has a low probability of entering the lower airways and triggering asthma [37]. In contrast, tree pollen allergens have been recorded in sizes that are small enough to enter the lower airways, which may cause asthmatic responses in susceptible people [38].

To the best of our knowledge, we are the first to report the relationship between the severity of AR and BA and the types of pollen allergens. Regarding AR, patients with moderate/severe intermittent AR showed the highest SPT positivity to maize pollen (29.2\%). Meanwhile, patients with moderate/severe persistent AR showed the highest SPT positivity to Timothy grass pollen (32.4\%). Patients with partially controlled asthma showed the highest positivity to maize pollen (30\%), which was also true for patients with uncontrolled asthma (37.5\%).

We compared the residency of the patients with the types of pollen and noticed that the most prevalent pollen types in rural and urban areas were Timothy grass (34.3\%) and maize (29.2\%), respectively, which means that grass pollen as a whole is prevalent throughout urban and rural areas. The high prevalence of 
grass pollen allergy in urban areas can be explained by the elevated levels of $\mathrm{CO} \otimes$ that have been shown to increase grass pollen production by $50 \%$ per flower [39]. Consistent with our results, a study conducted in Finland demonstrated that grass pollen exposure increased with the decreasing level of urbanization. This might be illustrated from the allergology point of view that the most urban environments, with small frequently managed patches of vegetation, have little potential to produce considerable amounts of pollen grains and to expose people to pollen. Thus, staying in urban environments would reduce the overall exposure to grass pollen, although occasionally higher levels of exposure may be encountered [31].

In addition, our study revealed that the prevalence of Bermuda grass pollen was higher in rural areas than in urban areas, and the difference was statistically significant ( $P$ value $=0.008)$. However, Jorge et al. in Colombia disagreed with this, and they aimed to explore whether the growth conditions of the Bermuda grass pollen modify the allergic response of patients with AR in rural versus urban areas. They concluded that Bermuda grass pollen was more prevalent in urban areas, and its growth conditions modify its allergenicity [40].

There were monthly variations in the frequency of exacerbations during the study period. Peaks of allergic respiratory diseases recorded in January, December, March, and June were 26.5\%, 21.5\%, 18\%, and $16 \%$, respectively. This could be explained by the higher rate of viral infections and allergen exposure during winter (December and January), pollination of the majority of pollen during spring (March), and when the grass pollen is at its peak (late spring) (June), with a lower level of exacerbation in summer when the climate becomes drier. Our results could be easily illustrated by research performed on the onset and duration of several allergenic pollen types in the USA, indicating that the start dates for the appearance of significant allergens is prevalent earlier in the year (January). Another fact is that grass pollen is present in the air during late spring and early summer (March and June) [22].

In this study, the most prevalent cross-reactive food with pollen, as evidenced by the SPTs, were oranges $(12 \%)$, followed by tomatoes $(11.5 \%)$ and soya $(11 \%)$. We demonstrated that tomatoes were highly crossreactive with Timothy grass (43.5\%) and maize pollen (39.1\%). Oranges were highly cross-reactive with cultivated rye and Russian thistle (33.3\%). Soya was highly cross-reactive with cultivated rye (36.4\%), Timothy grass (27.3\%), and Russian thistle (27.3\%). In line with our study, a paper published by the EAACI demonstrated that $60 \%$ of food allergies in adults are linked to an inhalant allergy [41]. Another study in Bosnia revealed that $50 \%$ of the study population was allergic to Timothy grass, which was highly correlated with tomatoes, melons, and peanuts [42]. Vieths et al. performed a study on the cross-reactivity between allergens and pollen, and they revealed that there was a significant cross-reaction between grass pollen and tomatoes and oranges. This may be attributed to the fact that profilins and cross-reactive carbohydrate determinants, which are present in grass pollen, are also present in different fruits and vegetables, such as oranges and tomatoes [43].

The limitations of this work are that it was conducted in a single center with a relatively small sample size. Moreover, the lack of molecular techniques to study the different allergens used in this study may 
add to our limitations.

In conclusion, pollen plays a substantial role in patients with respiratory allergies in Egypt. In addition, grass pollen is the most prevalent type of pollen, especially in urban areas.

\section{Declaration}

\section{- Ethics approval and consent to participate}

The study was conducted according to the Medical Association Declaration of Helsinki. Informed written consent was obtained from all the participants. The study had been reviewed and approved by the Research Ethics Committee at the Faculty of Medicine, Ain Shams University (reference MD 292/2017). This manuscript doesn't report on the use of any animal or human data or tissue.

\section{- Consent for publication}

Not applicable

\section{- Availability of data and materials}

All data sets generated during and/or analysed during the current study are available in this published article.

\section{- Authors' contributions}

MR designed the study. NN, MM were responsible for data collection. MM prepared the manuscript. OA, NA and EA shared in data analysis and critical revision of the manuscript. All authors read and approved the final manuscript.

\section{- Acknowledgement}

None

\section{- Competing interests}

The authors declare that they have no competing interests.

\section{- Funding}

The author(s) denies receipt of any financial support for the research, authorship, and/or publication of this article.

\section{- Conflict of interest}


The authors declare that no funding or grant was received for the study, and that they have no conflict of interest, financial or personal relationship related to the study.

We appreciate very much your time and your efforts.

\section{References}

1. Simoens S. The cost-effectiveness of immunotherapy for respiratory allergy: a review. European journal of allergy and clinical immunology. 2012; 67(9):1087-105

2. Xie ZJ, Guan K, Yin J. Advances in the clinical and mechanism research of pollen induced seasonal allergic asthma. Am J Clin Exp Immunol.2019; 8(1):1-8.

3. Taketomi EA, Sopelete MC, de Sousa Moreira PF, Vieira FD. Pollen allergic disease: pollens and its major allergens. Brazilian Journal of Otorhinolaryngology. 2006; 72(4):562-7.

4. Sedghy F, Varasteh AR, Sankian M, Moghadam M. Interaction between air pollutants and pollen grains: the role on the rising trend in allergy. Reports of biochemistry \& molecular biology. 2018; 6(2):219

5. Beggs PJ. Environmental allergens: from asthma to hay fever and beyond. Curr Clim Change Rep. 2015; 1:176-84.

6. Fann N, Brennan T, Dolwick P, et al. Air quality impacts. Research Gate. 2016; 69-98

7. Prescott R Potter P. Immunochemical characterization of grass pollen allergens in South Africa: review article. Biology. 2007.

8. James EN, Susan CA, Kate RW, et al. Estimates of present and future asthma emergency department visits associated with exposure to oak, birch, and grass pollen in the United States. Geohealth. 2019; $3(1): 11-27$.

9. Green BJ, Levetin E, Horner WE, Codina R, Barnes CS, Filley WV. Landscape plant selection criteria for the allergic patient. The Journal of Allergy and Clinical Immunology: In Practice.2018; 6(6):1869-76.

10. Stemeseder T, Hemmer W, Hawranek T and Gadermaier G. Marker allergens of weed pollen-basic considerations and diagnostic benefits in the clinical routine. Allergo J Int. 2014; 23:274-80.

11. Kim MA, Kim DK, Yang HJ, et al. Pollen-food allergy syndrome in Korean pollinosis patients. Allergy Asthma Immunol Res; 2018; 10(6):648-61.

12. Passali D, Bellusi LM, Kern EB, Sarafoleanu $C$ and Popescu FD. Genes, allergens and inflammation in allergic rhinitis. In: Rhinosinusal inflammation and infections: modern thinking and current treatment, editor. Bucharest: Editura Academiei Romane; 2013; 101-67.

13. Global Initiative for Asthma. Global Strategy for Asthma Management and Prevention, 2017.

14. Brożek JL, Bousquet J, Agache I, et al., Allergic rhinitis and its impact on asthma (ARIA) guidelines2016 revision. J Allergy Clin Immunol. 2017; 140(4):950-958.

15. Heinzerling L, Mari A, Bergmann KC, et al. The skin prick test-European standards, clinical and translational. Allergy; 2013; 3(1):3. 
16. Razi E and Moosavi GA. Serum total IgE levels and total eosinophil counts: relationship with treatment response in patients with acute asthma. J Bras Pneumol. 2010; 36(1):23-28.

17. Stoller JK, Basheda S, Laskowski D, et al. Trial of standard versus modified expiration to achieve endof-test spirometry criteria. Am Rev Respir Dis. 1993; 148(2):275-80.

18. Quanjer PH, Stanojevic S, Cole TJ, et al. ERS Global Lung Function Initiative. Multi-ethnic reference values for spirometry for the 3-95 yr age range. Eur Respir J. 2012; 40:1324-43

19. Pellegrino R, Viegi G, Brusasco V, et al. Interpretative strategies for lung function tests. Eur Respir J. 2005; 26:948-68.

20. Wang XY, Ma TT, Wang XY, et al. Prevalence of pollen-induced allergic rhinitis with high pollen exposure in grasslands of northern China. Allergy. 2018; 73(6):1232-43.

21. Strachan DP. Hay fever, hygiene, and household size. BMJ. 1989; 299(6710):1259-60.

22. Patel NP, Prizment AE, Thyagarajan $B$, et al. Urban versus rural residency and allergy prevalence among adult women. Ann Allergy Asthma Immunol.2018; 120(6):654-60.

23. Charles SB. Impact of climate change on pollen and respiratory disease. Current Allergy and Asthma Reports. 2018; (11):59.

24. Kim JH, Kim SH, Park HW, Cho SH, Chang YS. Oral allergy syndrome in birch pollen sensitized patients from a Korean University Hospital. J Korean Med Sci. 2018; 33(33):e218.

25. Assarehzadegan MA, Shakurnia A, Amini A. The most common aeroallergens in a tropical region in Southwestern Iran. World Allergy Organ J. 2013; 6:7

26. Frankland AW, El-Hefny A. House dust and mites as causes of inhalant allergic problems in the United Arab Republic. Clin Allergy.1971; 1(3):257-60

27. Goronfolah L. Aeroallergens, atopy and allergic rhinitis in the Middle East. Eur Ann Allergy Clin Immunol. 2016; 48(1):5-21.

28. Athanasios D, Claudia TH, Regina T. Climate change and pollen allergies. Biodiversity and Health in the Face of Climate Change. 2019; 47-66.

29. Roberts R, Boyle J, Crane SP, et al. Developments in the field of allergy in 2016 through the eyes of Clinical and Experimental Allergy. Clinical and Experimental Allergy. 2017; 47(12):1512-25.

30. Jung S, Estrella N, Pfaffl MW, Hartmann S, Handelshauser E, Menzel A. Grass pollen production and group $\mathrm{V}$ allergen content of agriculturally relevant species and cultivars. PLoS One. 2018; 13(3):e0193958

31. Timo $\mathrm{TH}$, Jan $\mathrm{H}$, Harri A, et al. Urbanity as a determinant of exposure to grass pollen in Helsinki Metropolitan area, Finland PLoS One. 2017; 9(11).

32. Aburuz S, Bulatova N, Tawalbeh M. Skin prick test reactivity to aeroallergens in Jordanian allergic rhinitis patients. East Mediterr Health J. 2011; 17(7):60410

33. Ezeamuzie Cl, Thomson MS, Al-Ali S, Dowaisan A, Khan M, Hijazi Z. Asthma in the desert: spectrum of the sensitizing aeroallergens. Allergy. 2000; 55(2):157-62.

34. Sørensen H, Ashoor AA, Maglad S. Perennial rhinitis in Saudi Arabia. Ann Allergy. 1986; 56(1):76-80. 
35. Zakzouk SM, Gad El-Rab MO. A study of clinical and allergic aspects of rhinitis patients in Riyadh. Ann Saudi Med. 1996; 16(5):550-5

36. Sung M, Kim SW, Kim JH, Lim DH. Regional difference of causative pollen in children with allergic rhinitis. J Korean Med Sci. 2017; 32(6):926-32.

37. Schäppi GF, Taylor PE, Pain MC, et al. Concentrations of major grass group 5 allergens in pollen grains and atmospheric particles: implications for hay fever and allergic asthma sufferers sensitized to grass pollen allergens. Clinical and experimental allergy. 2001; 29(5):633-41.

38. Taylor PE, Flagan RC, Miguel AG, Valenta R, Glovsky MM. Birch pollen rupture and the release of aerosols of respirable allergens. Clinical and experimental allergy. 2004; 34(10):1591-6.

39. Albertine JM, Manning WJ, DaCosta M, Stinson KA, Muilenberg ML, Rogers CA. Projected carbon dioxide to increase grass pollen and allergen exposure despite higher ozone levels. PLoS One.2014; 9(11):e111712.

40. Jorge $S$, Andres $S$ and Jorge S. Differences in the nasal inflammatory response to cynodon dactylon from rural and urban areas in patients with allergic rhinitis. Allergy Rhinol. 2018; 9:21

41. Werfel T, Asero R, Ballmer-Weber BK, et al. Position paper of the EAACl: food allergy due to immunological cross-reactions with common inhalant allergens. Allergy. 2015; 70(9):1079-90.

42. Focak M and Solakovic-Focak S. Cross-reactivity patterns between Timothy grass pollen and peanut, melon and tomato allergens: Bosnia and Herzegovina experience. Albanian Medical Journal. 2018; 7:11.

43. Vieths S, Scheurer S, Ballmer-Weber B. Current understanding of cross-reactivity of food allergens and pollen. Ann N Y Acad Sci. 2002; 964(1):47-68.

\section{Tables}


Table 1

Skin prick test with common aeroallergens $(n=200)$

\begin{tabular}{|c|c|c|}
\hline & No. & Percentage \\
\hline \multicolumn{3}{|l|}{ Pollen } \\
\hline Timothy grass & 57 & $28.5 \%$ \\
\hline Maize & 57 & $28.5 \%$ \\
\hline Russian thistle & 48 & $24.0 \%$ \\
\hline Cultivated rye & 46 & $23.0 \%$ \\
\hline Mugwort & 36 & $18.0 \%$ \\
\hline Alder & 32 & $16.0 \%$ \\
\hline Bermuda grass & 28 & $14.0 \%$ \\
\hline Ragweed & 26 & $13.0 \%$ \\
\hline Cultivated wheat & 25 & $12.5 \%$ \\
\hline Olive & 15 & $7.5 \%$ \\
\hline Elder & 14 & $7.0 \%$ \\
\hline Birch & 12 & $6.0 \%$ \\
\hline \multicolumn{3}{|l|}{ Animal dander } \\
\hline Cat fur & 26 & $13.0 \%$ \\
\hline \multicolumn{3}{|l|}{ Molds } \\
\hline Alternaria & 14 & $7.0 \%$ \\
\hline Aspergillus & 22 & $11.0 \%$ \\
\hline \multicolumn{3}{|l|}{ Dust mites } \\
\hline Dermatophagoides farinae & 56 & $28.0 \%$ \\
\hline Dermatophagoides pteronyssinus & 64 & $32.0 \%$ \\
\hline Data are presented as number (No. & and $p$ & centage (\%). \\
\hline
\end{tabular}


Table 2

Comparison of prevalence of different types of pollen in rural vs. urban areas

\begin{tabular}{|llllll|}
\hline & \multicolumn{2}{l}{ Rural $(\mathrm{n}=70)$} & \multicolumn{2}{l}{ Urban $(\mathrm{n}=130)$} \\
\cline { 2 - 6 } & $\mathrm{N}$ & $\%$ & $\mathrm{~N}$ & $\%$ & P value \\
\hline Timothy grass & 24 & $34.3 \%$ & 33 & $25.4 \%$ & 0.183 \\
\hline Bermuda grass & 16 & $22.9 \%$ & 12 & $9.2 \%$ & 0.008 \\
\hline Maize & 19 & $27.1 \%$ & 38 & $29.2 \%$ & 0.755 \\
\hline Cultivated rye & 13 & $18.6 \%$ & 33 & $25.4 \%$ & 0.275 \\
\hline Cultivated wheat & 11 & $15.7 \%$ & 14 & $10.8 \%$ & 0.313 \\
\hline Mugwort & 11 & $15.7 \%$ & 25 & $19.2 \%$ & 0.537 \\
\hline Russian thistle & 20 & $28.6 \%$ & 28 & $21.5 \%$ & 0.267 \\
\hline Ragweed & 8 & $11.4 \%$ & 18 & $13.8 \%$ & 0.628 \\
\hline Elder & 7 & $10.0 \%$ & 7 & $5.4 \%$ & 0.252 \\
\hline Birch & 6 & $8.6 \%$ & 6 & $4.6 \%$ & 0.350 \\
\hline Alder & 12 & $17.1 \%$ & 20 & $15.4 \%$ & 0.746 \\
\hline Olive & 7 & $10.0 \%$ & 8 & $6.2 \%$ & 0.325 \\
\hline Data presented as number (No.) and percentage (\%); values are significant if P $\leq 0.05$ \\
\hline
\end{tabular}


Table 3

Severity of allergic rhinitis and types of pollen

\begin{tabular}{|c|c|c|c|c|c|c|c|c|c|c|}
\hline \multirow{3}{*}{$\begin{array}{l}\text { Types of } \\
\text { pollen }\end{array}$} & \multirow{2}{*}{\multicolumn{2}{|c|}{$\begin{array}{l}\text { Total } \\
(n=173)\end{array}$}} & \multicolumn{8}{|c|}{ Severity of allergic rhinoconjunctivitis } \\
\hline & & & \multicolumn{2}{|c|}{$\begin{array}{l}\text { Mild } \\
\text { intermittent } \\
(n=9)\end{array}$} & \multicolumn{2}{|c|}{$\begin{array}{l}\text { Mild } \\
\text { persistent } \\
(n=4)\end{array}$} & \multicolumn{2}{|c|}{$\begin{array}{l}\text { Mod/severe } \\
\text { intermittent } \\
(n=89)\end{array}$} & \multicolumn{2}{|c|}{$\begin{array}{l}\text { Mod/severe } \\
\text { persistent } \\
(n=71)\end{array}$} \\
\hline & No. & $\%$ & No. & $\%$ & No. & $\%$ & No. & $\%$ & No. & $\%$ \\
\hline $\begin{array}{l}\text { Timothy } \\
\text { grass }\end{array}$ & 48 & 28.3 & 2 & 22.2 & 1 & 25.0 & 23 & 25.8 & 23 & 32.4 \\
\hline $\begin{array}{l}\text { Bermuda } \\
\text { grass }\end{array}$ & 25 & 14.5 & 1 & 11.1 & 2 & 50.0 & 11 & 12.4 & 11 & 15.5 \\
\hline Mugwort & 29 & 16.8 & 1 & 11.1 & 0 & 0.0 & 17 & 19.1 & 11 & 15.5 \\
\hline $\begin{array}{l}\text { Russian } \\
\text { thistle }\end{array}$ & 43 & 24.9 & 1 & 11.1 & 2 & 50.0 & 22 & 24.7 & 18 & 25.4 \\
\hline Ragweed & 24 & 13.9 & 1 & 11.1 & 0 & 0.0 & 13 & 14.6 & 10 & 14.1 \\
\hline Elder & 10 & 5.8 & 2 & 22.2 & 0 & 0.0 & 7 & 7.9 & 1 & 1.4 \\
\hline Birch & 12 & 6.9 & 1 & 11.1 & 0 & 0.0 & 5 & 5.6 & 6 & 8.5 \\
\hline Alder & 25 & 14.5 & 3 & 33.3 & 0 & 0.0 & 15 & 16.9 & 7 & 9.9 \\
\hline Maize & 48 & 27.7 & 3 & 33.3 & 0 & 0.0 & 26 & 29.2 & 19 & 26.8 \\
\hline $\begin{array}{l}\text { Cultivated } \\
\text { rye }\end{array}$ & 39 & 22.5 & 1 & 11.1 & 2 & 50.0 & 18 & 20.2 & 18 & 25.4 \\
\hline $\begin{array}{l}\text { Cultivated } \\
\text { wheat }\end{array}$ & 22 & 12.7 & 0 & 0.0 & 2 & 50.0 & 8 & 9.0 & 12 & 16.9 \\
\hline Olive & 14 & 8.1 & 1 & 11.1 & 0 & 0.0 & 6 & 6.7 & 7 & 9.9 \\
\hline
\end{tabular}


Table 4

Severity of bronchial asthma and types of pollen

\begin{tabular}{|c|c|c|c|c|c|c|c|c|}
\hline \multirow[t]{3}{*}{ Types of pollen } & \multirow{2}{*}{\multicolumn{2}{|c|}{$\begin{array}{l}\text { Total } \\
(n=83)\end{array}$}} & \multicolumn{6}{|c|}{ Severity of bronchial asthma } \\
\hline & & & \multicolumn{2}{|c|}{$\begin{array}{l}\text { Controlled } \\
(n=15)\end{array}$} & \multicolumn{2}{|c|}{$\begin{array}{l}\text { Partially controlled } \\
(n=60)\end{array}$} & \multicolumn{2}{|c|}{$\begin{array}{l}\text { Uncontrolled } \\
(n=8)\end{array}$} \\
\hline & No. & $\%$ & No. & $\%$ & No. & $\%$ & No. & $\%$ \\
\hline Timothy grass & 19 & 22.9 & 3 & 20.0 & 16 & 26.7 & 0 & 0.0 \\
\hline Bermuda grass & 10 & 12.0 & 0 & 0.0 & 10 & 16.7 & 0 & 0.0 \\
\hline Mugwort & 16 & 19.3 & 1 & 6.7 & 13 & 21.7 & 2 & 25.0 \\
\hline Russian thistle & 15 & 18.1 & 3 & 20.0 & 12 & 20.0 & 0 & 0.0 \\
\hline Ragweed & 9 & 10.8 & 1 & 6.7 & 6 & 10.0 & 2 & 25.0 \\
\hline Elder & 11 & 13.3 & 3 & 20.0 & 6 & 10.0 & 2 & 25.0 \\
\hline Birch & 2 & 2.4 & 0 & 0.0 & 1 & 1.7 & 1 & 12.5 \\
\hline Alder & 17 & 20.5 & 4 & 26.7 & 12 & 20.0 & 1 & 12.5 \\
\hline Maize & 22 & 26.5 & 1 & 6.7 & 18 & 30.0 & 3 & 37.5 \\
\hline Cultivated rye & 18 & 21.7 & 1 & 6.7 & 15 & 25.0 & 2 & 25.0 \\
\hline Cultivated wheat & 10 & 12.0 & 1 & 6.7 & 8 & 13.3 & 1 & 12.5 \\
\hline Olive & 6 & 7.2 & 1 & 6.7 & 3 & 5.0 & 2 & 25.0 \\
\hline
\end{tabular}


Table 5

Comparison between cross-reactive food and different types of pollen $(n=83)$

\begin{tabular}{|c|c|c|c|c|c|c|c|c|c|c|c|c|c|c|}
\hline \multirow{3}{*}{$\begin{array}{l}\text { Types of } \\
\text { pollen }\end{array}$} & \multicolumn{14}{|c|}{ Food } \\
\hline & \multicolumn{2}{|c|}{$\begin{array}{l}\text { Milk } \\
(n=15)\end{array}$} & \multicolumn{2}{|c|}{$\begin{array}{l}\text { Tomato } \\
(n=23)\end{array}$} & \multicolumn{2}{|c|}{$\begin{array}{l}\text { Egg whole } \\
(n=21)\end{array}$} & \multicolumn{2}{|c|}{$\begin{array}{l}\text { Wheat } \\
(n=16)\end{array}$} & \multicolumn{2}{|c|}{$\begin{array}{l}\text { Orange } \\
(n=24)\end{array}$} & \multicolumn{2}{|c|}{$\begin{array}{l}\text { Soya } \\
(n=22)\end{array}$} & \multicolumn{2}{|c|}{$\begin{array}{l}\text { M. nuts } \\
(n=16)\end{array}$} \\
\hline & $\mathbf{N}$ & $\%$ & $\mathbf{N}$ & $\%$ & $\mathbf{N}$ & $\%$ & $\mathbf{N}$ & $\%$ & $\mathbf{N}$ & $\%$ & $\mathbf{N}$ & $\%$ & $\mathbf{N}$ & $\%$ \\
\hline $\begin{array}{l}\text { Timothy } \\
\text { grass }\end{array}$ & 8 & 53.3 & 10 & 43.5 & 11 & 52.4 & 5 & 31.3 & 6 & 25.0 & 6 & 27.3 & 4 & 25.0 \\
\hline $\begin{array}{l}\text { Bermuda } \\
\text { grass }\end{array}$ & 2 & 13.3 & 6 & 26.1 & 2 & 9.5 & 5 & 31.3 & 4 & 16.7 & 2 & 9.1 & 3 & 18.8 \\
\hline Mugwort & 5 & 33.3 & 6 & 26.1 & 5 & 23.8 & 4 & 25.0 & 4 & 16.7 & 2 & 9.1 & 5 & 31.3 \\
\hline $\begin{array}{l}\text { Russian } \\
\text { thistle }\end{array}$ & 4 & 26.7 & 6 & 26.1 & 3 & 14.3 & 5 & 31.3 & 8 & 33.3 & 6 & 27.3 & 3 & 18.8 \\
\hline Ragweed & 3 & 20.0 & 2 & 8.7 & 2 & 9.5 & 1 & 6.3 & 4 & 16.7 & 3 & 13.6 & 2 & 12.5 \\
\hline Elder & 1 & 6.7 & 2 & 8.7 & 3 & 14.3 & 0 & 0.0 & 2 & 8.3 & 1 & 4.5 & 2 & 12.5 \\
\hline Birch & 0 & 0.0 & 3 & 13.0 & 1 & 4.8 & 1 & 6.3 & 1 & 4.2 & 2 & 9.1 & 1 & 6.3 \\
\hline Alder & 5 & 33.3 & 4 & 17.4 & 2 & 9.5 & 1 & 6.3 & 7 & 29.2 & 3 & 13.6 & 0 & 0.0 \\
\hline Maize & 8 & 53.3 & 9 & 39.1 & 7 & 33.3 & 5 & 31.3 & 6 & 25.0 & 4 & 18.2 & 5 & 31.3 \\
\hline $\begin{array}{l}\text { Cultivated } \\
\text { rye }\end{array}$ & 2 & 13.3 & 6 & 26.1 & 6 & 28.6 & 3 & 18.8 & 8 & 33.3 & 8 & 36.4 & 5 & 31.3 \\
\hline $\begin{array}{l}\text { Cultivated } \\
\text { wheat }\end{array}$ & 2 & 13.3 & 6 & 26.1 & 2 & 9.5 & 1 & 6.3 & 4 & 16.7 & 4 & 18.2 & 2 & 12.5 \\
\hline Olive & 3 & 20.0 & 3 & 13.0 & 3 & 14.3 & 3 & 18.8 & 2 & 8.3 & 4 & 18.2 & 3 & 18.8 \\
\hline
\end{tabular}

Figures 


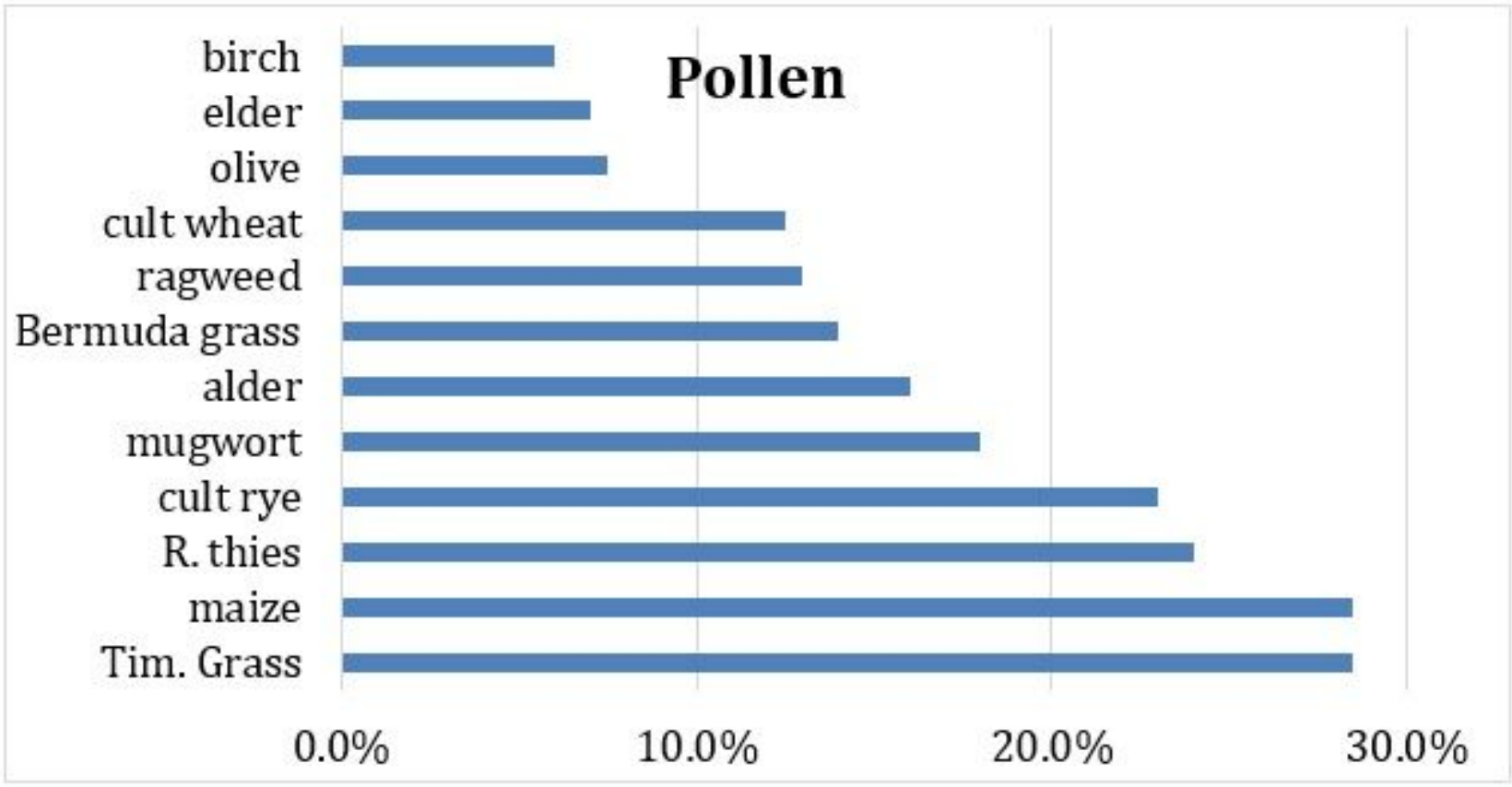

Figure 1

Prevalence of different pollen among patients with respiratory allergies (\%).

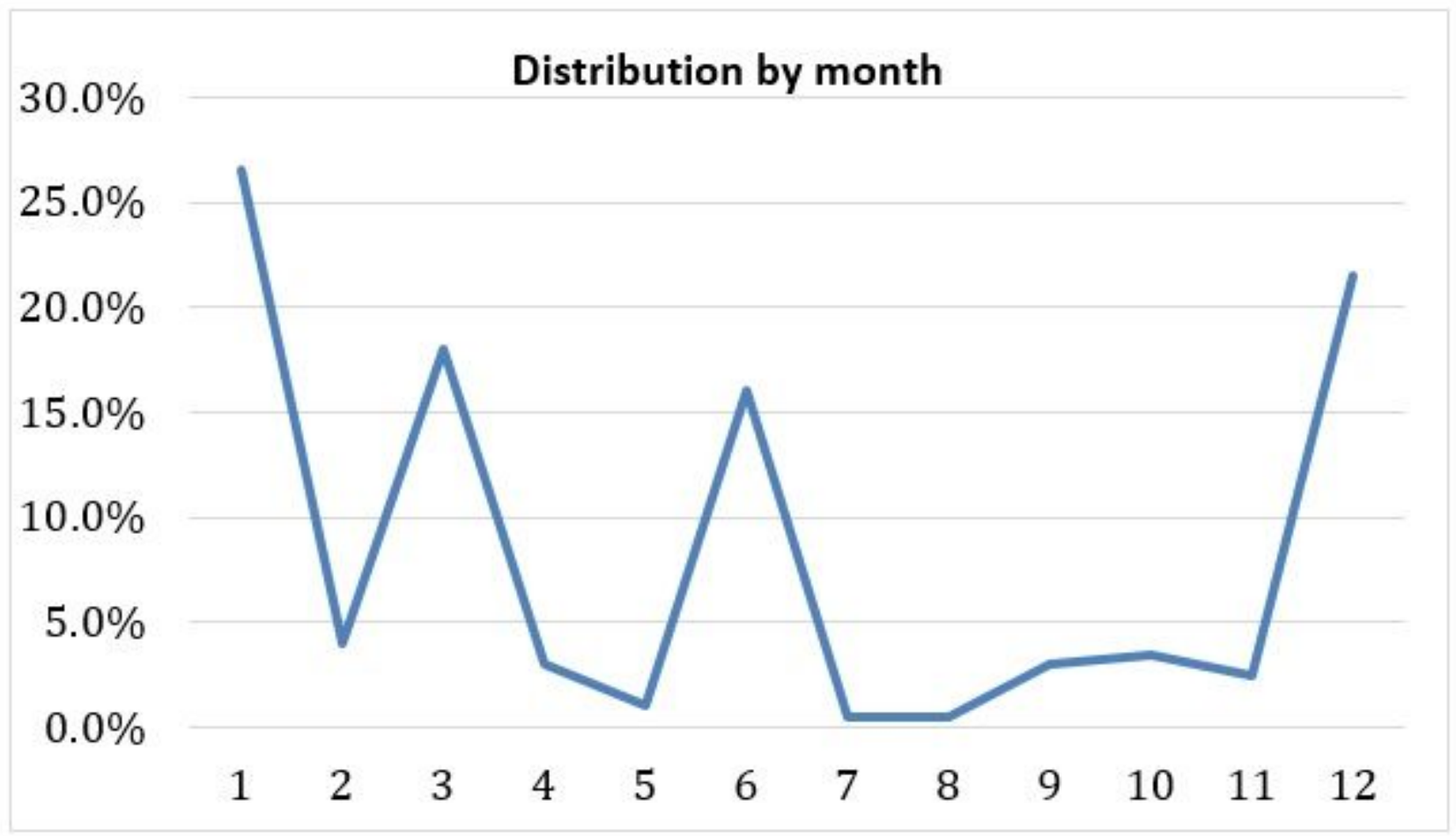

Figure 2

Peaks of exacerbation of respiratory allergies (there were multiple peaks when patients with allergic respiratory diseases suffered the most during certain months of the year). 